\title{
ANÁLISE DE IMPACTOS AMBIENTAIS DE MATERIAIS E SUBSISTEMAS CONSTRUTIVOS DE UMA EDIFICAÇÃO COM VIÉS SUSTENTÁVEL, EM FASE DE PROJETO
}

\author{
INGRID ZITTO | UFRGS \\ MIGUEL ALOYSIO SATTLER, PhD. | UFRGS
}

\section{INTRODUÇÃO}

É de conhecimento geral o grande impacto ambiental que a construção civil causa, sob diversos aspectos, tais como: extração de matérias primas; geração de altos volumes de resíduos; desmatamento; poluição de águas e ar. Diante deste quadro, é premente a necessidade de mitigar esses impactos, por meio de projetos que visem o aperfeiçoamento de técnicas construtivas e escolhas mais conscientes e adequadas de materiais. Assim, observa-se a relevância da avaliação de materiais e métodos construtivos, bem como da divulgação de tais procedimentos, junto aos profissionais envolvidos no setor da construção civil. Considerando isso, definiu-se como objetivo principal deste trabalho a avaliação ambiental dos subsistemas e materiais, a serem empregados na edificação em estudo. Já como objetivos secundários estabeleceu-se: (a) a identificação dos subsistemas e materiais construtivos previstos em projeto que possam minimizar impactos ambientais; (b) o refinamento do método a ser adotado para a avaliação de impactos ambientais.

\section{OBJETO DE ESTUDO}

O objeto de estudo desta pesquisa é uma edificação de pequeno porte, a ser construída no município de Feliz (RS), com a finalidade de sediar o CERES - Centro de Estudos Regenerativos e Sustentabilidade. O CERES, apresenta uma área compacta, de $58,55 \mathrm{~m}^{2}$, distribuídos em dois pavimentos. O seu projeto foi desenvolvido com base em princípios de sustentabilidade, como: utilização de materiais locais; reutilização de materiais existentes no local da construção; aproveitamento de parte da edificação existente; entre outros.

\section{MÉTODO DE AVALIAÇÃO}

A avaliação dos impactos ambientais dos materiais e subsistemas a serem adotados na edificação utilizou, como referência, o método aplicado por Kuhn (2006) em sua dissertação de mestrado, que foi aprimorado com a adição de dois novos itens, (f) e (g), identificados abaixo. Considerou-se sete critérios: (a) materiais não reaproveitáveis; (b) materiais sem potencial de reaproveitamento; (c) perdas de materiais; (d) quantificação de madeiras nativas; (e) pegada energética; (f) pegada de carbono; (g) pegada hídrica. Na fase inicial dos estudos, levantou-se o quantitativo de todos os subsistemas e materiais, por área. Em seguida, cada componente foi quantificado em termos de sua massa. Por fim, executou-se os cálculos cabíveis, para cada critério analisado. Na avaliação das pegadas, adotou-se índices unitários, que caracterizassem o potencial impacto gerado na produção desses materiais. Assim, obteve-se a quantidade total, por material e por subsistema analisado.

\section{CONCLUSÕES PARCIAIS}

Para cada tipo de material e subsistema, foram verificados ganhos ambientais em alguns critérios. No entanto, desvantagens foram identificadas em relação a outros critérios.

Constatou-se a importância da adequação do projeto aos objetivos almejados, bem como a sua adaptação ao local de implantação, otimizando o ajuste do projeto às especificidades de cada situação. Os resultados demonstram que, mesmo quando se procura minimizar os possíveis impactos, ainda ocorrem impactos de difícil controle. A pesquisa revela o quão complexa é a busca pela minimização de impactos da construção civil e a importância da utilização de indicadores para a sua redução.

\section{REFERÊNCIAS}

KUHN, E. A. Avaliação da sustentabilidade ambiental do protótipo de habitação de interesse social Alvorada. 2006. Dissertação (Mestrado em Engenharia Civil) - Escola de Engenharia, Programa de Pós Graduação em Engenharia Civil. Universidade Federal do Rio Grande do Sul, Porto Alegre. 
